\title{
Closure of population biobanks and direct-to-consumer genetic testing companies
}

\author{
Ma'n H. Zawati · Pascal Borry · Heidi Carmen Howard
}

Received: 12 May 2011 / Accepted: 24 May 2011 / Published online: 26 June 2011

(C) Springer-Verlag 2011

\begin{abstract}
Genetic research gained new momentum with the completion of the Human Genome Project in 2003. Formerly centered on the investigation of single-gene disorders, genetic research is increasingly targeting common complex diseases and in doing so is studying the whole genome, the environment and its impact on genomic variation. Consequently, biobanking initiatives have emerged around the world as a tool to sustain such progress. Whether they are small scale or longitudinal, public or private, commercial or non-commercial, biobanks should consider the possibility of closure. Interestingly, while raising important ethical issues, this topic has hardly been explored
\end{abstract}

M. H. Zawati $(\bowtie)$

Centre of Genomics and Policy, McGill University,

740 Dr. Penfield Avenue, Room 5209, Montréal,

QC H3A 1A4, Canada

e-mail: man.zawati@mcgill.ca

P. Borry $\cdot$ H. C. Howard

Centre for Biomedical Ethics and Law,

Katholieke Universiteit Leuven, BOX 7001,

Kapucijnenvoer 35, 3000 Leuven, Belgium

P. Borry

Department of Clinical Genetics,

EMGO Institute for Health and Care Research,

VU University Medical Center, PO Box 7057 ,

BS7, D439, NL-1007 MB Amsterdam, The Netherlands

P. Borry

Department of Medical Humanities, EMGO Institute for Health and Care Research, VU University Medical Center,

PO Box 7057, BS7, D439, NL-1007 MB Amsterdam,

The Netherlands

\section{H. C. Howard}

The Institute for Bioethics and Medical Ethics,

University of Basel, Missionstrasse 24,

CH-4056 Basel, Switzerland in the literature. Indeed, ethical issues associated with sale, insolvency, end of funding, or transfer of materials to other entities (which are all issues either related to or possible consequences of closure) are seldom the subject of discussion. In an attempt to fill this gap, this paper will discussusing population and direct-to-consumer (DTC) genetic testing companies' biobanks as case studies-(1) international and national normative documents addressing the issue of closure and (2) the internal policies of population biobanks and DTC genetic testing companies. The analysis will inform the debate on biobank closure and elucidate the underlying ethical issues, which include, but are not limited to informed consent, storage and privacy.

\section{Introduction}

Since their creation, biobanks have been credited for facilitating human genetic research. Recently, biobanks have included studies aiming to examine and understand diseases by analyzing genetic variation and gene-environment interactions in the general population (Thorisson et al. 2009). Today, biobankers constantly stress the need to collect larger numbers of samples and data over time, so as to achieve statistical significance (Burton et al. 2009). This "constant need" has amplified the important weight of already existing collections.

However, the statistical power of a collection is not the only factor that guarantees sustainability. Indeed, biobanks-defined as "an organized collection of human biological material and associated information stored for one or more research purposes" (P3G 2009)—depend on the availability of funding. This reality should theoretically, and from a purely managerial perspective, prompt biobanks to consider the potential and eventual end of their opera- 
tions. More particularly, what will happen to biological materials upon closure, whether unexpected or planned? Will the data and the samples be destroyed or will they be transferred to another entity? If transferred, what are the criteria that will need to be met before such transfer? What should participants be made aware of in the consent process with regard to closure of the biobank?

In order to assess these matters from across the publicprivate spectrum, population biobanks and direct-to-consumer (DTC) genetic testing companies are analyzed here as case studies. It is apparent that very little has been written on the ethical, legal and social issues of biobank closure. For population biobanks, the only publications on this issue pertain to a particular legal jurisdiction (Janger 2005; Rothstein 2005) or remain general in scope (Robertson 2003). Generally, any potential dissolution of a biobank should be addressed in the consent forms (Robertson 2003). Moreover, "bank organizers and their institutional affiliates have 'moral' duties not to waste those efforts by dissolving those banks without arranging for transfer of materials to new research entities" (Robertson 2003). No further discussion is provided on these moral duties or the underlying ethical or legal principles associated therewith.

Similarly, the ending of operations of companies that sell DTC genetic testing and that also bank client data (Howard et al. 2010) also raises similar questions. For example, what will happen to the genomic data and samples that are held by the company if the latter goes bankrupt or is sold to another entity? There are imminent reasons for concern. In November 2009, the biotech company deCODE Genetics, which markets the genetic service called deCODEme, filed a voluntary petition for relief under Chapter 11 of the U.S.A. Bankruptcy Code. Furthermore, there is no academic literature addressing the topic of closure for DTC genetic testing companies.

In order to address the issue of closure in the context of population biobanking and DTC genetic testing companies, this article first discusses international and national normative documents (Centre of Genomics and Policy 2011 HumGen International Database). Second, this article will provide some examples from population biobanks and DTC genetic testing companies on how their consent forms and internal policies address closure. The result of these analyses will inform further discussion on the underlying ethical issues raised by biobank closures.

\section{How do population biobanks address closure?}

\section{Population biobanks: governance}

To further our understanding of common disease risk and human health, population genomics draws on basic data on genomic variation and on lifestyle behaviors and environmental factors (Khoury 2004). But the study of normal genomic variation across whole populations requires the collection of data and biological samples from individuals on a longitudinal scale (Khoury 2004; Knoppers and Abdul-Rahman (Zawati) 2008). Accordingly, large-scale population biobanking initiatives have thrived around the world. As for their characterization, population biobanks have been defined as:

"a collection of biological materials that has the following characteristics: (i) the collection has a population basis; (ii) it is established, or has been converted, to supply biological materials or data derived therefrom for multiple future research projects; (iii) it contains biological materials and associated personal data, which may include or be linked to genealogical, medical and lifestyle data and which may be regularly updated; (iv) it receives and supplies materials in an organized manner" (Council of Europe 2006).

In fact, the level of organization of population biobanks is crucial to their long-term sustainability. Such organization generally implies the existence of consent procedures for recruitment, access mechanisms for national and international collaborations and management policies for internal procedural arrangements.

With respect to governance, we can differentiate between two general types of biobanks: "legislatively regulated" and "self-regulated" (Cutter et al. 2004). The former are created following the adoption of a legal instrument delineating their use, structure and operation (Cutter et al. 2004). These instruments usually take the form of laws or regulations and are either biobank-specific or general (i.e. largely governing genetic research that collects samples and data). As for "self-regulated" biobanks, their use, structure and operations usually follow non-binding normative documents, such as guidelines, opinions and statements (Cutter et al. 2004).

Population biobanks: legislation and closure

Using the HumGen International Database, we retrieved biobank legislation addressing the issue of closure from Iceland, Sweden and Norway.

Iceland's Biobanks Act of 2000 (Government of Iceland 2000) was the first piece of European legislation specifically dealing with biobanks. The Act states that in order to establish a biobank, a licence must be granted by the Minister of Health following the receipt of recommendations from the Medical Director of Health and the National Bioethics Committee. The only mention of closure in this law relates to the preservation of biological samples. Indeed, it asserts that if the licensee decides to cease operations of the 
biobank or "should the licence have been revoked [...] the Minister shall, after receiving recommendations [...] make a decision on the disposal of the biobank, taking into account the wishes and proposals of the licensee" (Government of Iceland 2000). Moreover, the Act also mentions the possibility of closure as a punitive measure. It states that if "the licensee or its employees violate the terms of the Act or government directives on the basis of the Act, $[\ldots]$ the conditions of the licence are not fulfilled, or if the licensee proves unable to operate the biobank", the Minister could revoke the licence provided under the terms of this Act. Two types of revocation are mentioned: one which allows "a reasonable period of grace to rectify matters" (Government of Iceland 2000) and another that is more abrupt, without notification or possibility for rectification. The Biobanks Act mentions no ethical or legal issues relating to the end of operations nor does it set-as a precondition to the licence-the existence of a plan for closure.

Norway's 2003 Act Relating to Biobanks (Government of Norway 2003) does, however, request such a plan to establish a research biobank. The researcher must provide the regional committee for medical research ethics a notification containing various information, including "the length of time for which the biobank is to be maintained and what will be done with the material when it is closed down". This notification will also be considered by the Ministry in question in the Act and if the information provided does not satisfy ethical considerations or important societal interests, the biobank may not be established. The Act does not specify the scope of such ethical considerations or nature of these social interests. It does mention, however, that the Ministry might decide, if closure is inevitable, to maintain the biobank or transfer its material to another biobank, given the importance of its contents.

Another example of a law that discusses closure is Sweden's Biobanks in Medical Care Act of 2003 (Government of Sweden 2003). Yet, this legislation only mentions that if the materials of a biobank are no longer significant for its agreed purpose and where there is no public interest to maintain its specimens, the biobank could close down and its specimens destroyed or returned to the care provider. There is no mention of any requirement for a closure plan or on the need to disclose such a possibility to the participants during consent procedures.

In 2010, the Swedish Ministry of Health and Social Affairs formulated proposals for the amendment of the 2003 Act and published its Inquiry's propositions in a Report entitled A New Biobanks Act (Government of Sweden 2010). In the latter, the Inquiry "considers that permission from the National Board of Health and Welfare is to be required before a biobank or tissue samples may be transferred to another principal. Special grounds will still be required before granting permission for a transfer" (Gov- ernment of Sweden 2010). Moreover, "the Inquiry proposes that when assessing whether or not there are special grounds for a transfer, the extent to which the donor's interests can be upheld following the transfer are to be considered" (Government of Sweden 2010).

Finally, the Council of Europe's Recommendation Rec (2006) 4 of the Committee of Ministers to Member States on Research on Biological Materials of Human Origin mentions only that specific procedures must be in place for the transfer or the closing of a population biobank (Council of Europe 2006). There is no mention whatsoever of the underlying ethical or legal concerns with such transfer or closure and whether any plan should be disclosed to prospective participants.

Population biobanks: guidelines and closure

The most significant international guidance on the issue of biobanks closure is found in the Organisation for Economic Co-operation and Development (OECD)'s 2009 Guidelines on Human Biobanks and Genetic Research Databases (Organisation for Economic Co-operation and Development 2009). Reserving a distinct section on the "Discontinuation of the Human Biobanks and Genetic Research Databases (HBGRD) and disposal of materials and data", the OECD's Guidelines state that biobanks should develop a plan for unexpected discontinuations. They mention the termination of funding and the lack of scientific purposiveness as possible reasons for discontinuation.

Moreover, the Guidelines state that researchers must develop "plans for the appropriate transfer, disposition and destruction of human biological materials and data" (Organisation for Economic Co-operation and Development 2009), which shall be done in accordance with the research protocol, legislation and regulation and the participant's informed consent (Organisation for Economic Co-operation and Development 2009). On that particular issue, the OECD Guidelines present an interesting approach in the event that biobanks have no other choice but to close down. They state that the operators of such a biobank should indeed "consider the transfer of its resources to another entity" (Organisation for Economic Co-operation and Development 2009). Just like Norway's Act Relating to Biobanks, the OECD guidelines emphasize the need to maximize the use of the participants' data and samples. It, however, adds an interesting condition to such transfer: "the operators should ensure that the recipient has in place equivalent policies, governance structure, equipment and systems, and staff" (Organisation for Economic Co-operation and Development 2009).

The German National Ethics Council's 2004 Biobanks for Research document serves as an example of a national normative document addressing the issue of closure. It 
insists that the best approach to handling closure is to adhere to what's stated in the participants' consent form. The German document states that the information contained in the consent form should extend to biobank closure and to the possibility of transferring the biobank as a whole to a third party for the sake of minimizing the loss of "valuable potential research material". Moreover, the National Ethics Council provides that in the absence of participants' consent on the issue, such transfer is acceptable if the data and samples are anonymized and if they are transferred to an equivalent institution (university to university and commercial sector to commercial sector). It does not request, however, that biobanks ensure that the third party abide by the same policies, as the OECD Guidelines demand. The Council's 2010 Human Biobanks for Research (German National Ethics Council 2010) does not provide further guidance on the issue.

Population biobanks and closure: current practices

Having reviewed the existing legislative and self-regulatory normative documents on the topic of biobank closure, we deemed it important to assess how population biobanks addressed the topic in their internal policies. The consent forms and access and management policies of 28 population biobanks were reviewed. Our review was limited by several factors, namely the language barrier, the fact that some documentation is currently unavailable, and the fact that some biobank websites do not provide public access to their policies. Nonetheless, the following examples serve to illustrate the current strategies of population biobanks on closure.

CARTaGENE, a Quebec-based population biobank resource, states in its Management Policy (CARTaGENE 2009) that it "will keep operating as long as its funding allows for the continuation of its activities, its objectives set at the time it was created and until sufficient robust measures to ensure the confidentiality of CARTaGENE's contents can be maintained" (CARTaGENE 2009). It specifies that the institutional review board of the host institution may then authorize the destruction or the transfer of data and samples to another trustee. There is no mention of the need to ensure that the other institutional trustee has equivalent policies, governance structure, equipment and systems or staff.

Another example of a biobank that has tackled the issue of ending of operations in length is LifeGene-a Swedish population biobank. Its Ethics Policy (LifeGene 2009) document specifies that:

"LifeGene will have a detailed strategy for handling contingencies in the event that LifeGene has to close or make other substantial transitions in the holdings or control of the resource. This will address the possibility of partial or full transfer of the resource, whether elective or as a result of insolvent liquidation. The objective is to ensure that the protection and respect for the rights of the participants provided by this Ethics Policy document continue to be maintained. Information about such measures will be made available to participants" (LifeGene 2009).

As for the UK Biobank, its Ethics and Governance Framework states that a detailed strategy will be developed for handling "contingencies in the event that the UK Biobank charitable company has to close or make other substantial transitions in the holdings or control of the resource." According to the Framework, "the objective will be to ensure that the protection and respect for the rights of the participants provided by this Framework continue to be maintained [...]" (UK Biobank 2006). Lastly, it highlights that information about any measures planned for such events will be made available to participants.

\section{"Biobanking" by DTC genetic testing companies: how is closure addressed?}

\section{DTC genetic testing and biobanking}

The term DTC genetic testing has been described as either the marketing and/or the offer of genetic tests directly to the public without an intermediate health care professional (Genetics and Public Policy Center 2006; Mitchell et al. 2010). One type of service offered by some DTC genetic testing companies is known as full genome testing (Howard et al. 2010) or genome scanning (McGowan et al. 2010) or genome-wide-testing (GWT). Such testing involves the genotyping of hundreds of thousands to millions of genetic markers (often single nucleotide polymorphisms, SNPs) throughout the genome. Although this amount of data is not equivalent to that produced by sequencing the entire genome (approximately 3 billion data points), it still involves a great deal of data that can easily fuel numerous genomic studies in the immediateand medium-term future. Many of the DTC genetic testing companies performing GWT destroy both the saliva and DNA samples of consumers but retain the data generated for further research (Howard et al. 2010). As such, they can be considered data repositories. These (mostly private) companies were not necessarily included in the traditional definition of biobanks. We include them here as they are nevertheless genetic data repositories accessed by different entities conducting genetic and genomic research (Howard et al. 2010). Therefore, as in the case for traditional biobanks, the (lack of) established provisions for the closure 
or sale of a DTC genetic testing company also raises ethical issues.

Normative documents regarding DTC genetic testing companies and closure

The 19 normative documents regarding DTC genetic testing found in the "Guidelines, Laws and Policies" section of the DTCgen module of the HumGen International Database (Centre of Genomics and Policy DTCGen 2011) were scrutinized for information on the closure of a DTC genetic testing company. Of the 19 normative documents studied, only 4 addressed the issue of closure (Table 1). That being said, the statements made are relatively vague and do not discuss the issue in any great depth. The Secretary's Advisory Committee on Genetics, Health and Society merely mentions the issue in passing. Meanwhile, the European Society of Human Genetics (ESHG) statement and the Nuffield Council Report from the United Kingdom are a bit more specific but remain brief. The ESHG maintains that: "companies offering DTC genetic tests should... have a clearly laid out plan as to what will happen to the samples and data should the company be sold or go bankrupt" (ESHG 2010). The Nuffield Council states: "We recommend that all companies that provide genetic analysis for susceptibility to common multifactorial diseases should make... arrangements for data security (including in case of any changes to the administration of the company)". Finally, the Human Genetics Commission's 2010 Common Framework of Principles for Direct-to-Consumer Genetic Testing Services is more specific and pointed with its recommendations but still falls short of providing an elaborate "how-to" guide for companies. While personal and genetic data are to be disposed of securely or transferred under the same terms of consent originally provided by the consumer, the Principles fail to mention how this would be enforced or controlled between companies.

DTC genetic testing companies and closure: current practices

We also studied the websites (including consent forms, privacy policies, terms of use, and service agreements) of four DTC companies offering GWT in order to retrieve information regarding the end of operations (Table 2). Namely, we studied the websites of the companies 23 andMe, deCODE (for the service deCODEme), Navigenics and Pathway Genomics. Although there are many more companies which sell genetic testing services DTC, these four companies sell GWT (as opposed to single-gene or multi-gene testing), are relatively well known, and perform some form of research with consumer data (Howard et al. 2010; Pathway Genomics 2010).
All four companies do mention the possibility of a merger or acquisition (Table 2). Three of the companies (23andMe, deCODE and Pathway Genomics) explicitly state that in the event of a merger or acquisition the acquiring company would have to comply with the provisions of the existing privacy statements. However, none of the companies appear to address the issue of closure in-depth, especially not vis-à-vis information for consumers.

\section{Discussion}

An important and obvious conclusion from the above is that there is a dearth of information available on both population and DTC genetic testing company biobank closure. Indeed, the earliest mention of closure in normative documents governing population studies is from Iceland's Biobanks Act of 2000, while in-depth discussion is found in the OECD's 2009 Guidelines (Organisation for Economic Cooperation and Development 2009). The same could be said about DTC genetic testing companies.

Although striking, one could argue that this scarcity is somewhat comprehensible. Most of these population biobanks are relatively new and are still working on their recruiting and seeking long-term sustainability. Moreover, issues such as consent, confidentiality, access and international collaboration (Zawati et al. 2011; Knoppers 2010) have been prioritized over specific procedures associated with closure of particular biobanks. Although understandable, it is still a concern given that biobanks and DTC genetic testing companies have been actively recruiting participants/consumers. Furthermore, as has been shown by the recent closure of onCore UK and the UK Human Tissue Bank, biobanks are not immune to termination (Stephens 2011).

As for the documents discussing closure, emphasis was put on the issue of disclosing the biobanks' plans during the initial consent process. Although not mentioned in laws and regulations, this issue is embedded in selfregulatory policies and guidelines, such as the German National Ethics Council's 2004 Biobanks for Research document, the OECD's Guidelines on HBGRDs and the internal policies of some population and DTC genetic testing biobanks. That being said, the fact that not all of the biobanks reviewed mention their plans for closure in the initial consent documentation could be problematic in the long run since most guidelines discussing consent highlight the importance of providing the participants with the necessary information on storage of both their data and samples (Council for International Organizations of Medical Science 2002; European Society of Human Genetics 2003; Organisation for Economic Co-operation and Development 2009). 
Table 1 Normative documents addressing DTC genetic testing and closure

\begin{tabular}{ll}
\hline $\begin{array}{l}\text { Normative document } \\
\text { (organization, year) }\end{array}$ & $\begin{array}{l}\text { Portion of documents addressing end of operations of } \\
\text { companies selling genetic testing directly to consumers }\end{array}$ \\
\hline
\end{tabular}

A Common Framework of Principles for Direct-to Consumer Genetic Testing Services (Human Genetics Commission, 2010)

Direct-to-Consumer Genetic Testing-Report of the Secretary's Advisory Committee on Genetics, Health, and Society (SACGHS, 2010)

Medical Profiling and Online Medicine: the ethics of 'personalized healthcare' in a consumer age (Nuffield Council on Bioethics, 2010)

Statement of the ESHG on Direct-to-Consumer Genetic Testing for Health Purposes (European Society of Human Genetics, 2010)
"4.1 The test provider should supply easily understood, accurate, appropriate and adequate information, which is also available in accessible formats, to consumers before obtaining consent for a genetic test. The following should be provided:

-information about what will happen to consumers' biological samples, and personal and genetic data, if the company ceases trading."

"7.4 If a test provider ceases trading, they should dispose of personal and genetic data securely or provide for transfer of responsibilities in accordance with the terms of consent given by the consumer."

"8.1 The use, storage, transfer and disposal of biological samples provided for genetic testing should be carried out in accordance with applicable legal, ethical and professional standards. The nature, purpose and maximum duration of the storage should be specified."

"8.3 If a test provider ceases trading, they should dispose of consumers' biological samples securely or provide for transfer of responsibilities in accordance with the terms of consent given by the consumer."

Privacy protections

"Gurwitz and Bregman-Eschet explain that privacy interests also can be compromised if a genetic testing company decides to sell its database containing the genotypic and phenotypic information of its customers to a third party. For commercial biotechnology companies, databases that contain genetic information are some of their most valuable assets. A company might sell its database in case of financial difficulty or simply for the sake of making a profit, just as it might do with any other valuable asset. Many consumers may be unaware of this possibility. In the absence of a Federal law prohibiting the sale of personal genetic information and in view of previous court decisions allowing the transfer of personal information from one entity to another, the unrestricted sale or transfer of genetic information to a third party may be a real possibility. In such cases, personal information might be transferred to a company with less strict privacy protection mechanisms. This issue also raises the question of ownership of genotypic and phenotypic information stored in the database. Who owns the information?"

"If a specimen and information retrieved from it are considered the property of the company collecting and storing it, then the company is free to treat it as any other commodity, including selling or transferring the information to a third party. One possible solution, as described by Winickoff and Winickoff, is to define the holder of genetic information as the "trustee" of the information it holds. This model would apply restrictions and responsibilities to the safekeeping of genetic information collected and stored by companies offering DTC genetic tests. For example, it would place restrictions on the transferability of information collected and future disclosures in the absence of consent from the customer."

Data protection

"9.23...Even if a company guaranteed security, if it went into administration or changed hands, there is no guarantee that the data held would be used for the same purposes for which it was originally gathered. For example, following the bankruptcy filing of the company deCODE genetics in 2009 and the purchase of most of the assets by another organisation, it remains unclear what exactly will happen to the personal genetic data held by deCODE genetics. Although the company has stated that the data will be used in the manner that it was prior to their bankruptcy, it has been argued that deCODE's new owners remain (legally) free to alter or expand their use of genetic data within a range of allowable uses."

In Europe, if a company goes into administration or changes hands, the data should be used only in accordance with the original consents or other lawfully authorized purposes. But this obligation does not apply to all jurisdictions and consumers may find it difficult to enforce even in Europe

...

9.51 We recommend that all companies that provide genetic analysis for susceptibility to common multifactorial diseases should make the following information prominently available in lay language for the consumer before they buy:... arrangements for data security (including in case of any changes to the administration of the company)."

Respect for private life

"Any genetic test should always be performed with respect for private life. In particular, companies offering DTC genetic tests should preserve the customer's privacy, keep their data confidential, inform them about their security procedures, explain what will happen to the sample and the data when the testing process is concluded, and have a clearly laid-out plan as to what will happen to the samples and data should the company be sold or go bankrupt. Privacy and confidentiality of the results, as well as possible consequences related to their disclosure to third parties, such as insurance companies and employers, should be discussed, when appropriate, as well as the property of the biological material and its fate after the results are confirmed." 
Table 2 Information available on websites of companies selling DTC genome-wide-testing

\begin{tabular}{|c|c|c|}
\hline $\begin{array}{l}\text { Company } \\
\text { name }\end{array}$ & $\begin{array}{l}\text { Section of } \\
\text { website }\end{array}$ & Information regarding closure \\
\hline deCODE & Terms of use & $\begin{array}{l}\text { "deCODE will not intentionally share your personal information with third parties without your express } \\
\text { consent except (i) to contractors deCODE uses to support its business (e.g., fulfillment services, technical } \\
\text { support, and delivery services), in which case deCODE will require such third parties to agree to treat such } \\
\text { information in accordance with this Privacy Policy, (ii) in connection with the sale, assignment, or other } \\
\text { transfer of the business of this Website to which the information relates, in which case deCODE will require } \\
\text { any such buyer to agree to treat such information in accordance with this Privacy Policy, or (iii) where re- } \\
\text { quired by applicable laws, court orders, or government regulations." (http://www.decodeme.com/terms-of- } \\
\text { use, accessed March 10, 2011) }\end{array}$ \\
\hline \multirow[t]{2}{*}{23 andMe } & $\begin{array}{l}\text { Privacy } \\
\text { statement }\end{array}$ & $\begin{array}{l}\text { "Business transitions } \\
\text { In the event that } 23 \text { andMe goes through a business transition such as a merger, acquisition by another com- } \\
\text { pany, or sale of all or a portion of its assets, your Personal Information will likely be among the assets trans- } \\
\text { ferred. In such a case, your information would remain subject to the promises made in any pre-existing } \\
\text { Privacy Statement." } \\
\text { (https://www.23andme.com/about/privacy/, accessed March 10, 2011) }\end{array}$ \\
\hline & $\begin{array}{l}\text { Consent } \\
\text { document }\end{array}$ & $\begin{array}{l}\text { "Could my participation end without my consent? } \\
\text { The } 23 \text { andWe study may be terminated without your consent. In the following cases, 23andMe will main- } \\
\text { tain your Genetic \& Self-Reported Information according to the terms of our Privacy Statement. } \\
\text { Transfer of ownership. If } 23 \text { andMe undergoes a business transition such as an acquisition or merger, the } \\
23 \text { andWe research study may be terminated. } 23 \text { andMe will require an acquiring company or merger agree- } \\
\text { ment to uphold the material terms of our Privacy Statement." } \\
\text { (https://www. } 23 \text { andme.com/about/consent/, accessed March 10, 2011) }\end{array}$ \\
\hline Navigenics & $\begin{array}{l}\text { Privacy } \\
\text { policy }\end{array}$ & $\begin{array}{l}\text { "However, we will not, without your explicit consent, disclose or share personally identifiable information } \\
\text { about you with third parties except as required to provide the services you have requested, in the event Nav- } \\
\text { igenics is acquired by or merges into another company, or as otherwise required by applicable law. We limit } \\
\text { access to Your Account Information and other personally identifiable information about you to appropriate } \\
\text { Navigenics personnel on a need-to-know basis." (http://www.navigenics.com/visitor/what_we_offer/ } \\
\text { our_policies/privacy/, accessed March 10, 2011) }\end{array}$ \\
\hline $\begin{array}{l}\text { Pathway } \\
\text { genomics }\end{array}$ & $\begin{array}{l}\text { Privacy } \\
\text { statement }\end{array}$ & $\begin{array}{l}\text { "If Pathway enters into a business transaction, such as a merger, acquisition by another company, selling } \\
\text { some or all of its assets, or bankruptcy, your personal information will, in most instances, be part of the } \\
\text { assets transferred. We will require the acquiring company to comply with the material provisions of the Full } \\
\text { Privacy Statement upon entering into such business transaction." (https://www.pathway.com/about-us/pri- } \\
\text { vacy-policy, accessed March 10, 2011) }\end{array}$ \\
\hline
\end{tabular}

Another element clearly mentioned in documents discussing closure is the need to protect the privacy of participants when transferring data and samples. This is not only mentioned in the OECD's 2009 Guidelines-where the transfer is conditional to the recipient having equivalent governance and resources-but in some DTC genetic testing companies' internal policies, which stress the need to honour the Privacy Statement or Policy following the transfer of information. Some population biobanks state that data and samples will be transferred to institutions that will protect and respect the participants' rights if closure occurs. But again, the fact that such an approach is not omnipresent in many population and DTC genetic testing biobanks' internal policies could be viewed negatively, especially with the growing challenges facing the protection of privacy in the genomics era (Church et al. 2009).

Additionally, the need to maximize the use of participant's data and samples is another element present in some of the documents analyzed above. This is clearly shown in Norway's 2003 Act Relating to Biobanks (Government of Norway 2003) and the 2009 OECD Guidelines on
$H B G R D s$. Indeed, as previously mentioned, the need to collect data and samples in some studies is crucial to achieve statistical significance, and hence, already existing collections have an important weight. Stemming from the emerging ethical trend of reciprocity, striving to realize the full benefit of research to which participants have given their data and samples is considered by some as an ethical imperative, provided that confidentiality is protected (European Society of Human Genetics 2003).

In conclusion, there is a need for clearer institutional frameworks on the issue of closure. In order to do that, normative documents will need to be adopted to provide efficient guidance on the matter. For biobankers, the most valuable asset is the trust of their participants in their endeavors (Knoppers and Abdul-Rahman (Zawati) 2009), a trust that requires the provision of all necessary information during the consent process and the existence of reasonable and adequate mechanisms to protect their privacy and the security of their data and samples. Through more active discussion on the issue of closure and transparency in their internal policies and protocols, population biobanks and 
DTC companies will continue to uphold this trust; i.e., of course, if they want to continue "reaping the benefits that should flow from the coming revelations about the genome" (Collins 2010) effectively in the years to come.

Acknowledgments MZ is funded by the European Council's Erasmus Mundus Scholarship and the Canadian Partnership for Tomorrow Project; PB is funded by the Research Fund Flanders (FWO); HCH is funded by the European Commission FP7 Marie Curie initiative. The authors would like to thank Amélie Rioux, Michael Le Huynh and Adrian Thorogood for their assistance.

Conflict of interest The authors declare that they have no conflict of interests.

\section{References}

Burton PR, Hansell AL, Fortier I, Manolio TA, Khoury MJ, Little J, Elliott P (2009) Size matters: just how big is BIG? Int J Epidemiol 38(1):263-273

CARTaGENE (2009) Cartagene management policy version 2.1. http:// www.cartagene.qc.ca/images/stories/cartagene $\% 20$ management $\%$ 20policy\%20dec09.pdf. Accessed 15 April 2011

Centre of Genomics and Policy (2011) HumGen International Database. http://www.humgen.org/int/index_lang.cfm?lang=2. Accessed 18 February 2011

Centre of Genomics and Policy DTCGen (2011) International database on the legal and socio-ethical aspects of population genetics. http://www.dtcgenetest.org. Accessed 18 February 2011

Church G, Heeney C, Hawkins N, de Vries J, Boddington P, Kaye J, Bobrow M, Weir B, Consortium PG (2009) Public access to genome-wide data: five views on balancing research with privacy and protection. PLoS Genet 5(10):e1000665

Collins F (2010) Has the revolution arrived? Nature 464(7289):674-675

Council for International Organizations of Medical Science (2002) International ethical guidelines for biomedical research involving human subjects. http://www.cioms.ch/publications/layout_guide 2002.pdf. Accessed 26 April 2011

Council of Europe (2006) Recommendation rec(2006)4 of the Committee of Ministers to Member States on Research on Biological Materials of Human Origin. https://wcd.coe.int/wcd/ViewDoc.jsp?id=977859

Cutter AM, Wilson S, Chadwick R (2004) Balancing powers: examining models of biobank governance. J Int Biotechnol Law 1(5):187-192

European Society of Human Genetics (2003) Data storage and DNA banking for biomedical research: technical, social and ethical issues. Eur J Hum Genet 11(Suppl 2):8-10. doi:10.1038/sj.ejhg. 5201115

European Society of Human Genetics (ESHG) (2010) Statement of the ESHG on direct-to-consumer genetic testing for health-related purposes. Eur J Hum Genet 18:1-3

Genetics and Public Policy Center (2006) Direct-to-consumer genetic testing: empowering or endangering the public? http://www. dnapolicy.org/policy.issue.php?action=detail\&issuebrief_id=32. Accessed 17 February 2011

German National Ethics Council (2010) Human biobanks for research. http://www.ethikrat.org/files/der_opinion_human-biobanks.pdf. Accessed 26 April 2011
Government of Iceland, Ministry of Welfare (2000) Act on biobanks. http://eng.velferdarraduneyti.is/acts-of-Parliament/nr/20093. Accessed 26 April 2011

Government of Norway (2003) Act relating to biobanks. European Commission. http://ec.europa.eu/research/biosociety/pdf/ norwegian_act_biobanks.pdf. Accessed 26 April 2011

Government of Sweden, Ministry of Health and Social Affairs (2003) Biobanks in medical care act. http://www.sweden.gov.se/content/ 1/c6/02/31/26/f69e36fd.pdf. Accessed 26 April 2011

Government of Sweden, Ministry of Health and Social Affairs (2010) A new biobanks act (Swedish Government Official Report). http:// www.regeringen.se/content/1/c6/15/65/67/d5441333.pdf. Accessed 26 April 2011 (in Swedish)

Howard HC, Knoppers BM, Borry P (2010) Blurring lines. EMBO Rep 11:579-582

Janger EJ (2005) Genetic information, privacy and insolvency. J Law Med Ethics 33(1):79-88

Khoury MJ (2004) The case for a global human genome epidemiology initiative. Nat Genet 36:1027-1028

Knoppers BM (2010) Return of individual research results: why the fuss? Gravitas 43(4): 17

Knoppers BM, Abdul-Rahman (Zawati) MH (2008) Biobanks in the literature. In: Elger B, Biller-Andorno N, Capron AM (eds) Ethical issues in governing biobanks: global perspectives. Ashgate Publishing, Hampshire

Knoppers BM, Abdul-Rahman (Zawati) MH (2009) Health privacy in genetic research: populations and persons. Politics Life Sci 28(2):99-101

LifeGene (2009) LifeGene ethics policy version 3.2. http://lifegene.ki.se/ethical_issues/documents/ 090331LifeGeneEthicsPolicyv32.pdf. Accessed 26 April 2011

McGowan ML, Fishman JR, Lambrix MA (2010) Personal genomics and individual identities: motivations and moral imperatives of early users. New Genet Soc 29(3):261-290

Mitchell PB, Meiser B, Wilde A, Fullerton J, Donald J, Wilhelm K, Schofield PR (2010) Predictive and diagnostic genetic testing in psychiatry. Clin Lab Med 30:829-846

Organisation for Economic Co-operation and Development (2009) Guidelines on human biobanks and genetic research databases

Pathway Genomics (2010) Privacy statement. https://www.pathway.com/about-us/privacy-policy. Accessed 10 March 2011

P3G and Phoebe Consortia (2009) The P3G Lexicon. http://www. p3gobservatory.org/lexicon/list.htm. Accessed 18 February 2011

Robertson JA (2003) Ethical and legal issues in genetic biobanking. In: Knoppers BM (ed) Populations and genetics: legal and socio-ethical perspectives. Brill Academic Publishers, Leiden, pp 297-309

Rothstein MA (2005) Expanding the ethical analysis of biobanks. J Law Med Ethics 33:89-101

Stephens N (2011) onCore UK: the $£ 4 \mathrm{~m}$ cancer tissue bank that closed. Newsl ESRC Genomics Netw 13:21-23

Thorisson GA, Muilu J, Brookes AJ (2009) Genotype-phenotype databases: challenges and solutions for the post-genomic era. Nat Rev Genet 10(1):9-18

UK Biobank (2006) Ethics \& governance framework version 2.0. http://www.ukbiobank.ac.uk/docs/EGF_Version2_July\%2006\% 20most\%20uptodate.pdf. Accessed 26 April 2011

Zawati M, Van Ness B, Knoppers B (2011) Incidental findings in genomic research: a review of international norms. GenEdit 9(1):1-8 